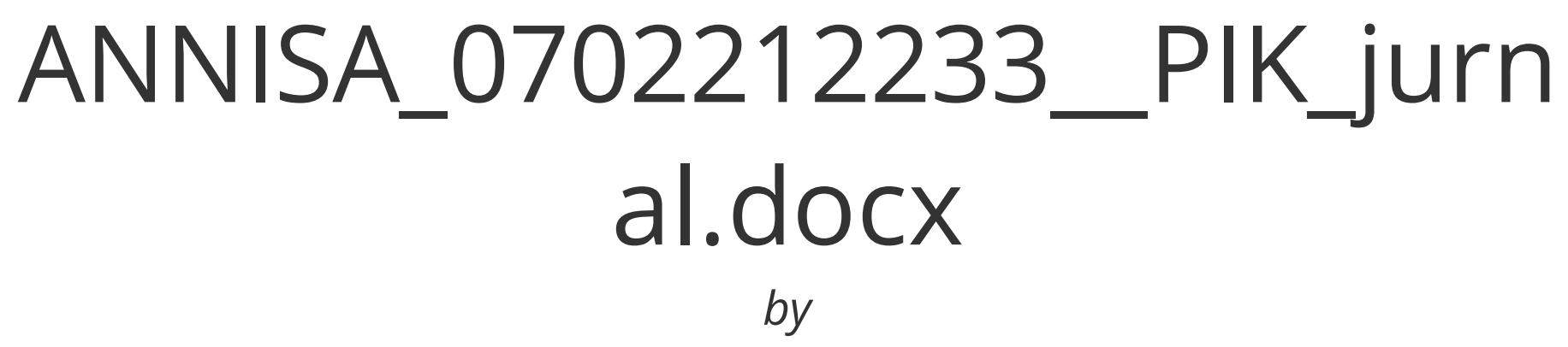

Submission date: 06-Jan-2022 08:59AM (UTC+0700)

Submission ID: 1737954498

File name: ANNISA_0702212233_PIK_jurnal.docx (561.79K)

Word count: 3389

Character count: 23413 


\title{
ANALISIS PERANGKAT LUNAK KOMPUTER SISTEM INFORMASI MANAJEMEN
}

\author{
ANNISA FADILA (0702212233) \\ SISTEM INFORMASI-6 FST UIN
}

Sumatera Utara Medan 2021/2022

afadilla213@gmail.com

\begin{abstract}
Abstrak
Perangkat lunak adalah program yang mengontrol aktivitas kerangka kerja PC. Ini juga merupakan pengembangan strategi dan program dokumentasi yang secara efektif menyelesaikan masalah yang dialami kehendaki. Komputer dicirikan sebagai sekelompok gadget elektronik yang menggabungkan bagian satu sama lain untuk membuat data yang baru-baru ini ditangani. Windows adalah sekelompok kerangka kerja yang dibuat oleh Microsoft, memanfaatkan UI grafis. UNIX adalah sistem operasi yang dikembangkan dalam bahasa $\mathrm{C}$, dan server biasanya menggunakan kerangka kerja UNIX. LINUX adalah kerangka kerja gratis dan terbuka (sumber terbuka) dengan izin GPL (GNU-Overall population Permit) yang penyampaian dan kemajuannya harus dimungkinkan tanpa syarat dengan memasukkan kode program pertama sebagai anak perusahaan. DOS (Plate Working Framework) adalah kerangka kerja yang terletak pada urutan teks yang bekerja pada perintah singkat. Kerangka kerja ini adalah pola dasar Windows.
\end{abstract}

Kata kunci : Windows, Unix, Linux, DOS dan Sistem Operasi Lain

\section{A. PENDAHULUAN}

$\begin{array}{lr}1 & \\ \text { Perangkat } & \text { Lunak adalah } \\ \text { sekumpulan data elektronik yang }\end{array}$

tersimpan dan dikendalikan oleh perangkat komputer. 
43 Komputer adalah seperangkat mesin elektronik yang bekerja sama dan secara otomatis dapat memproses data/garis tindakan menggunakan instruksi atau instruksi yang dihasilkan oleh suatu program.

25

Robert H. Blissmer mendefinisikan komputer sebagai perangkat elektronik yang mampu melakukan beberapa tugas: menerima, memproses instruksi, menyimpan pesanan, memproses hasil, dan memberikan keluaran berupa informasi.

Sistem informasi manajemen
adalah bagian dari sistem perencanaan
pengendalian internal bisnis yang
mencakup penggunaan orang,
dokumen, teknik, dan prosedur dalam
akuntansi manajemen untuk
memecahkan masalah bisnis, seperti
biaya produk, layanan, atau strategi
bisnis.

\section{B. TINJAUAN PUSTAKA}

Software, sifatnya berbeda dengan peralatan (equipment). Jika peralatan adalah komponen fisik yang dapat dilihat dan disentuh manusia, maka perangkat lunak secara fisik tidak terlihat dan tidak terlihat, dan perangkat lunak bukanlah objek yang terlihat dan tidak berwujud secara fisik, tetapi kita dapat melakukannya. Kontrol itu. ... (Samsudin dkk.: 2019: 73).

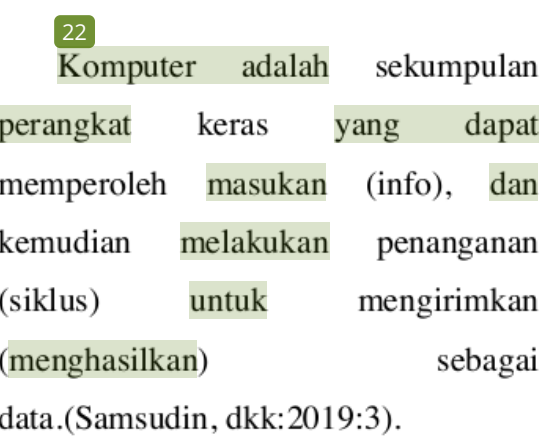

14

Perangkat lunak adalah program komputer di mana instruksi dapat dengan mudah dimodifikasi. Perangkat lunak biasanya digunakan untuk mengontrol perangkat keras (kadang disebut sebagai driver perangkat), melakukan perhitungan, dan berinteraksi dengan perangkat lunak sederhana lainnya (seperti sistem operasi dan bahasa pemrograman)

Sistem manajemen informasi adalah suatu proses manajemen yang memiliki sistem dengan fungsi yang mirip dengan otak komputer, salah 
satunya adalah menyediakan data

informasi kepada pengguna yang membutuhkannya. (McLord: 2020)

\section{6}

\section{METODE PENELITIAN}

Pada penelitian ini, metode yang saya terapkan ialah metode kunjungan pada sumber bahan penelitian. Kunjungan dilakukan pada halaman world wide web (site visit) dan dari berbagai jurnal.

Tidak hanya dari link, penelitian dikutip dari sumber buku bacaan " Pengenalan Komputer dan Teknologi Informasi" karya Bapak Samsudin, dkk:2019, dari buku bacaan "Sistem Informasi Akuntansi" karya Seprida Hanum, S.E., S.S., M.Si, dari buku Sutabri Tata, (2016) "Sistem Informasi Manajemen", dan dari buku Abdul Karim, (2020) "Teknologi Informasi dan Sistem Informasi Manajemen”

Dapat ditarik kesimpulan dari berbagai kutipan diatas bahwa perangkat lunak Software) merupakan salah satu elemen penting dari sebuah komputer atau perangkat teknologi lainnya. Tanpa perangkat lunak, komputer hanyalah benda mati.

\section{HASIL DAN PEMBAHASAN}

Perkembangan perangkat lunak (software) dimulai dengan lahirnya komputer elektronik. Perangkat lunak ini pertama kali dibuat oleh Charles Babbage pada pertengahan 1800-an. Namun, hal itu tidak diungkapkan secara resmi pada tahun 1935 oleh Alan Turing dalam sebuah esai berjudul "Bilangan Komputasi dalam Penerapan Masalah Entscheidung".

Turing yang merupakan seorang ahli matematika menjadi orang yang pertama kali mencetuskan bahwa komputer dapat menjalankan beragam program dan dapat digunakan untuk berbagai keperluan. Selain itu, Pada tahun 1930 .

\subsection{Pengertian Software}

Pemrograman adalah panduan pasti yang telah dibuat dan digunakan untuk memulai kapasitas peralatan. Pemrograman dibedakan menjadi 4 klasifikasi, yaitu:

\section{Perangkat Lunak Sistem Operai}

Operasi sytem adalah pemrograman yang mampu menyelesaikan tugastugas yang berhubungan dengan semua latihan PC, misalnya, mendukung 
aktivitas kerangka kerja aplikasi dan mengendalikan kelola aplikasi dan kelola semua gadget PC anda agar dapat berfungsi sesuai fungsinya. Kerangka kerja mengontrol semua aset PC dan memberikan premis di mana program aplikasi dapat disusun atau dijalankan. Ada beberapa kerangka kerja yang sering digunakan juga dibagi menjadi 4 , yaitu:

a. Windows

Windows merupakan framework kerja yang dibuat oleh Microsoft, dimana framework kerja ini memberikan antarmuka grafis GUI (Graphical UI) sehingga lebih mudah untuk bekerja. Dengan windows, klien tidak perlu mengetik pesanan melalui baris pesanan seperti di MSDOS. Pada dasarnya dengan memanfaatkan mouse atau console, klien dapat memberikan perintah untuk membuka menu, kotak wacana, menjalankan

aplikasi, menghapus dokumen, dll. Adapun fungsi dari windows, lebih spesifiknya:
- Hubungkan aplikasi dan perangkat keras sehingga dapat diintegrasikan untuk kinerja yang konsisten dan andal.

- Kontrol dan kelola sumber daya yang berjalan, termasuk perangkat lunak dan perangkat keras komputer Anda.

- Mengelola proses persiapan, perencanaan dan pemantauan program yang sedang berjalan.

- Mengelola dan mengontrol data input dan output.

Adapun contoh windows dari versi awal hingga versi saat ini, mari simak windows berikut ini.

Windows 1- November 1985

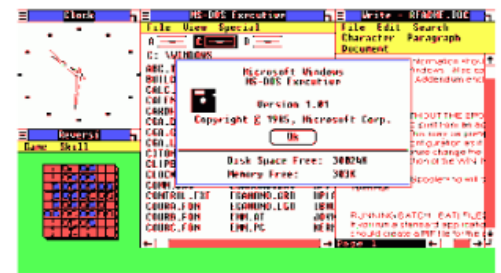

Windows 3- Mei 1990

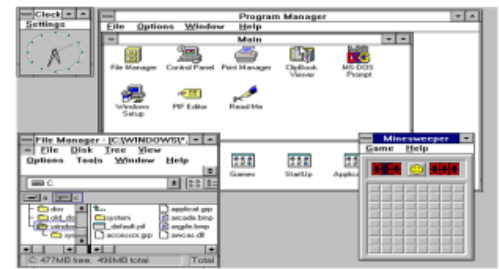

Windows 98- Mei 1998 


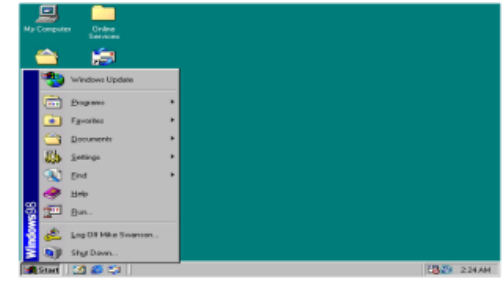

Windows XP-Agustus 2001

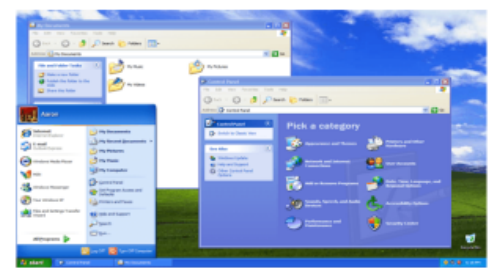

Windows 7- Juli 2009

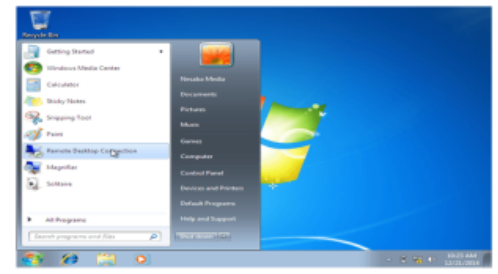

\section{Windows 8.1- Oktober 2013}

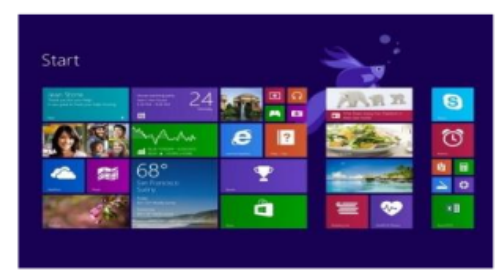

Windows 10- Juli 2015

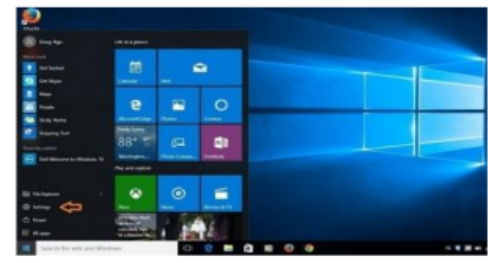

Jadi, kita akan membahas pengertian Windows beserta fitur dan contohnya. Setiap versi memiliki pro dan kontra, jadi saya lebih memilih untuk mempertahankan versi windows yang mereka miliki atau menggantinya dengan yang lebih baru.

b. UNIX

UNIX adalah sistem operasi untuk sistem operasi komputer yang dimulai pada tahun 1965 sebagai bagian dari proyek Multiplexed Information and Computing Service (Multics) yang dilakukan bersama oleh American Telephone and Telegraph (AT\&T), General Electric (GE), dan Institut Teknologi Maashusset (MIT) pada tahun 1965. tidak bertemu. Alamat: Pengeluaran Departemen Pertahanan AS. UNIX dirancang sebagai sistem operasi portabel, multitasking dan multi-pengguna. Adapun fungsi UNIX:

- Sistem multi-pengguna dapat digunakan oleh lebih dari satu orang pada saat yang bersamaan. 
- Multitasking, suatu sistem dapat melakukan banyak tugas atau proses pada saat yang bersamaan.

- Organisasi file Sistem File UNIX memiliki struktur file dan direktori seperti pohon.

- Shell, Shell adalah antarmuka pengguna sistem UNIX.S

- UNIX Utilities memiliki lebih dari 200 utilitas yang dapat Anda gunakan untuk mengelola sistem Anda.

Email, UNIX memiliki kemampuan untuk mengirim email antar administrator dalam lingkungan sistem UNIX.

Terdapat 3 komponen yang ada pada UNIX diantaranya :

$>$ Kernel

Development Environment

Commands

Tampilan pada sistem UNIX versi 7
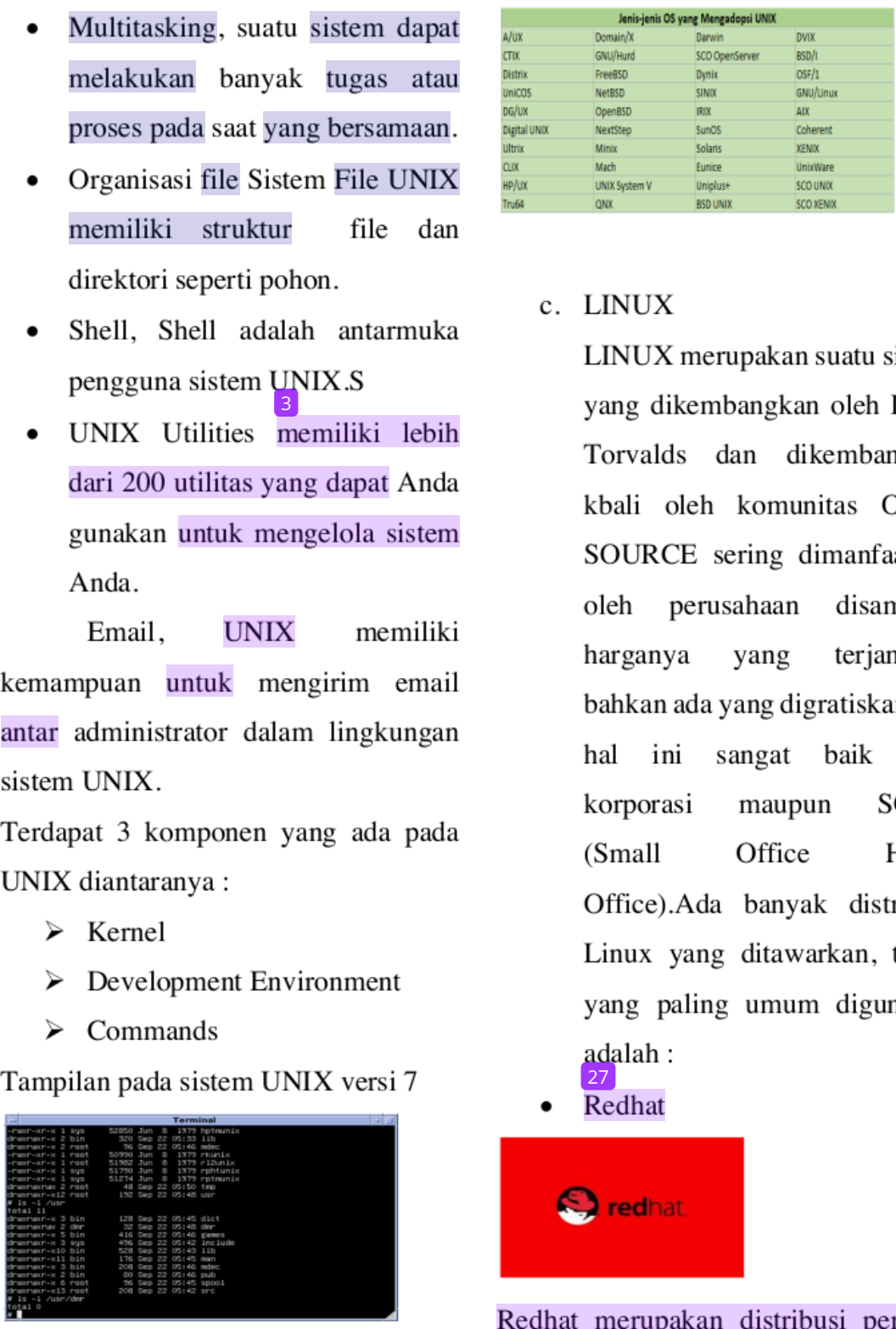

\section{c. LINUX}

LINUX merupakan suatu sistem yang dikembangkan oleh Linus Torvalds dan dikembangkan kbali oleh komunitas OPEN SOURCE sering dimanfaatkan oleh perusahaan disamping harganya yang terjangkau bahkan ada yang digratiskan dan hal ini sangat baik oleh korporasi maupun SOHO (Small Office Home Office).Ada banyak distribusi Linux yang ditawarkan, tetapi yang paling umum digunakan adalah : 27

- Redhat

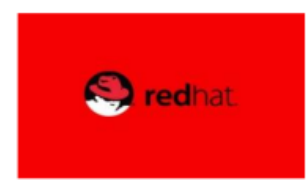

Redhat merupakan distribusi pertama yang instalasi dan pengoperasiannya

Contoh Sistem Operasi UNIX mudah.

- Debian 


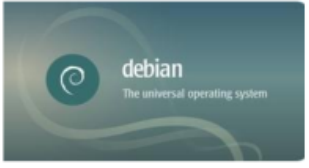

Debian merupakan distribusi yang mengutamakankestabilan

dankehandalan, meskipunmengorbankan

aspek kemudahan dankemutakhiran program.

- Slackware

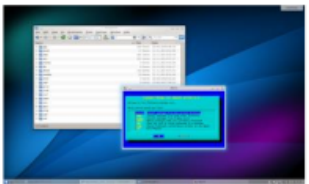

Slackware merupakan distribusi yang pernah paling unggul didunia Linux.

- SuSE

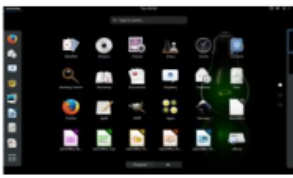

SuSE adalah sirkulasi yang sangat terkenal dengan YaST (Satu Instrumen Pengaturan lagi) untuk merancang kerangka kerja. SuSE adalah sirkulasi utama di mana pendirian dapat menggunakan bahasa Indonesia.

- Mandrake

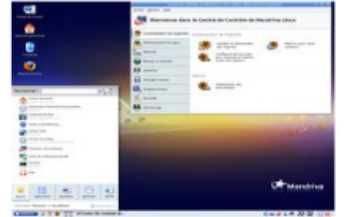

Mandrake adalah variasi dari penyebaran RedHat yang ditingkatkan untuk Pentium.

- WinLinux

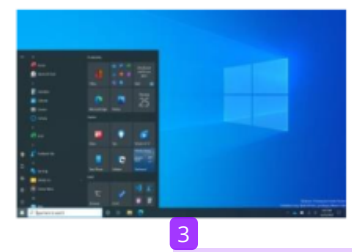

WinLinux merupakan suatu program aplikasi under Windows.

Sistem Linux tersusun atas tiga komponen penting yaitu :

a. Inti yang menyediakan semua fitur yang Anda butuhkan untuk menjalankan proses, dan menyediakan layanan sistem Menyediakan manajemen dan perlindungan akses ke sumber daya perangkat keras, termasuk memori virtual.

b. Perpustakaan sistem yaitu, menentukan kumpulan fungsi standar dimana aplikasi dapat berinteraksi dengan kernel, dan mengimplementasi atas kernel. 
45

c. Utilitas sistem adalah program yang melakukan tugas administratif tertentu.

Manfaat Linux/Unix dibandingkan pemrograman lain:

a. Linux/Unix memberikan beberapa proses spesial beberapa siklus unik di mana terminal, printer, dan perangkat peralatan lainnya dapat diakses seperti kita mengakses dokumen yang disimpan di piring atau lingkaran keras .

b. Linux adalah program sumber terbuka gratis.

c. Linux bergantung pada siklus 32 64 , jadi kecepatannya solid.

d. Keamanan informasi yang lebih baik

e. Linux dapat berjalan pada berbagai macam tahapan peralatan mulai dari Intel (x86), hingga prosesor RISC.

f. Linux menawarkan jenis bantuan untuk membuat, mengubah proyek, siklus, dan catatan.

\section{d. DOS dan Sistem Operasi Lain DOS adalah kerangka kerja} yang digunakan untuk menangani setiap aset di PC. Klien berinteraksi dengan
DOS dengan menyediakan pesanan menggunakan konsol PC. Klien harus mengetik pesanan dengan konsol, kemudian, pada saat itu, pesanan yang diberikan akan ditafsirkan oleh kerangka DOS seperti yang ditunjukkan oleh kapasitas pesanan. Pada tingkat dasar, pesanan pada kerangka kerja DOS diisolasi menjadi 2 jenis pesanan, yaitu pesanan dalam dan pesanan luar.

Singkatan dasar yang digunakan dalam DOS adalah path yang diikuti dengan tanda besar $(>)$, seperti $C: \$, $\mathrm{C}:\lfloor\mathrm{DOS} \backslash$, dan lain-lain. Pelanggan juga dapat menggunakan gambar pendek lainnya dengan menggunakan pesanan singkat.

Kerangka kerja ini juga bersifat single-entrusting (dapat menjalankan setiap program secara bergantian), menjalankan prosesor dalam mode asli (genuine mode), dan dapat menjalankan setiap klien secara bergantian (single client). Keluarga DOS dipartisi menjadi beberapa kelas, khususnya:

MSDOS (Microsoft Plate Working Framework), Tandy DOS, Compaq DOS, QDOS (Down to Business Working Framework), dan beberapa klon dari framework MSDOS yang 
disediakan oleh pembuat

IBM

PC/Viable PC Framework.

IBM Worldwide Business Machine PC Circle Working Framework (PCDOS) masih diproduksi oleh Microsoft, tetapi telah sedikit dimodifikasi untuk digunakan pada IBM PC

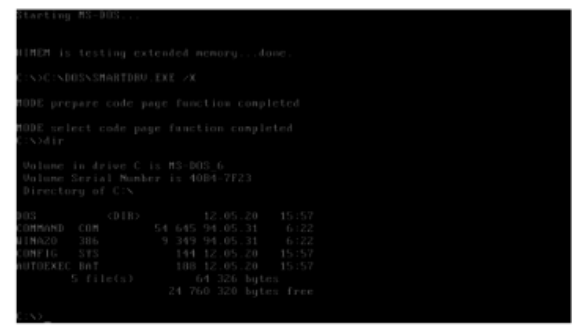

Tangkapan layar yang menunjukkan layar boot, antarmuka baris perintah, DR-DOS

(Computerized Exploration Circle Working Framework), dibuat oleh pencipta kerangka kerja $\mathrm{CP} / \mathrm{M}$, Gary Kildall.

$>$ Novell's Own Association, adalah versi DR-DOS yang dijual ke Novell karena perusahaan yang membawahi $\mathrm{CP} / \mathrm{M}$ bangkrut (Novell mengakuisisi Computerized Exploration Joined).

$>$ Caldera DOS, adalah bentuk Novell Individual Netware yang ditawarkan ke Caldera Enterprise.

FreeDOS, adalah bentuk DOS yang dibuat dari sisa pengembangan Caldera DOS, yang dibuat oleh area lokal sumber terbuka.

dan struktur direktori MS-DOS 6

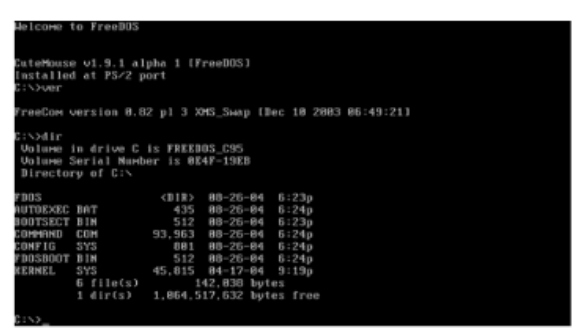

Tangkapan layar yang menunjukkan layar boot, antarmuka baris perintah, informasi versi, dan struktur direktori FreeDOS

\section{$\stackrel{2}{\text { Perintah internal MS-DOS }}$}

- Menggunakan dir sebagai daftar file dan direktori

Contoh Sintaks: dir c: Daftar file pada drive $\mathrm{c}$.

- Dell, seperti menghapus satu atau lebih file

Contoh sintaks: hapus del file.txt dan file.txt Direktori Aktif

- Copy, menjadi menyalin arsip menurut satu direktori ke direktori lainnya 


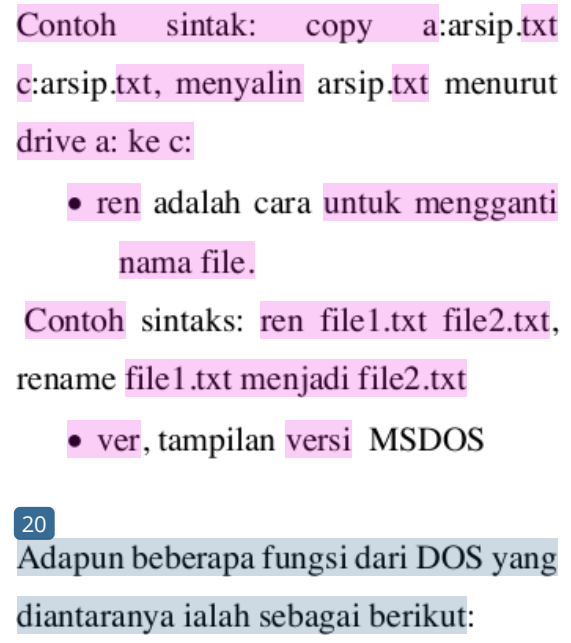

- ren adalah cara untuk mengganti nama file.

Contoh sintaks: ren file1.txt file2.txt, rename file1.txt menjadi file2.txt

- ver, tampilan versi MSDOS

20

Adapun beberapa fungsi dari DOS yang diantaranya ialah sebagai berikut:

- Mengontrol atau mengatur aktivitas komputer.

- Mengontrol proses input dan output data dari komputer.

- Mengelola memori komputer.

- Mengelola file dan direktori.

2. Perangkat Lunak Bahasa Pemrograman 24 Perangkat lunak bahasa pemrograman adalah perangkat lunak yang digunakan untuk menerjemahkan instruksi yang ditulis dalam bahasa pemrograman ke dalam bahasa mesin sehingga komputer dapat memahaminya. Berikut ini adalah contoh bahasa pemrograman yang digunakan.

- $\mathrm{C}++$ (Turbo $\mathrm{C}++)$

- Visual Basic (non-.NET)
- PHP (prosedural)

- Delphi (Borland)

- Pascal (Turbo Pascal)

- Java

- JSP

- ASP

a. Bahasa tingkat rendah, bahasa pemrograman jenis ini sangat sulit dimengerti karena instruksinya menggunakan bahasa mesin. Contoh bahasa pemrograman tingkat rendah adalah Bahasa mesin (machine language)

b. Bahasa tingkat menengah, merupakan bahasa pemrograman tingkat menengah dimana penggunaan instruksi sudah mendekati bahasa seharihari, walaupun begitu masih sulit untuk dimengerti. Contoh bahasa pemrograman tingkat menengah:

- Assembler

- Microsoft Macro Assembler (MASM)

- Bahasa C

Bahasa yang umum digunakan oleh perusahaan didalam menerapkan aplikasi SIA yaitu:

a.PHP 
Bahasa pemrograman ini merupakan bahasa program yang digunakan untuk mengembangkan halaman web dinamis.

Contoh:
28
$<$ html $>$
$<$ head $>$
$<$ title $>$ Percobaan $\mathrm{PHP}<$ title $>$
$</$ head $>$
$<$ body $>$
$<$ p $>$ Salam dari Hostinger $<$ p $>$
$</$ body $>$
$</$ html $>$

b. $\mathrm{C}++$ cout $<<$ endl;

cout<<"Masukan Nama : ";

cin $>$ nama;

cout<<"Masukan Nilai Tugas : ";

cin $>>$ tugas;

cout $<<$ "Masukan Nilai UTS : ";

cin $>$ uts;

cout<<"Masukan Nilai UAS : ";

cin $>$ uas;

int ntugas $=0.20 *$ tugas;

int nuts $=0.30 *$ uts;

int nuas $=0.50 *$ uas;

ini

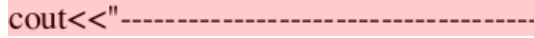

- "<<endl;

dikembangkan untuk menambah fitur berorientasi objek dengan bahasa $\mathrm{C}$ dengan penambahan kelas dan fitur lainnya.

Contoh:

\#include <conio.h $>$

\#include <iostream.h>

\#include <string >

void main ()

\{

string nama;

int tugas;

int uts;

int uas;

cout $<<$ "DAFTAR

NILAI int total $=$ ntugas + nuts + nuas;

cout $<<$ Nama Nilai Tugas Nilai

UTS Nilai UAS "<<endl;

cout<<"----------------------------------------

"<<endl;

cout $<<$ nama $<<$ " "<<tugas $<<$ " x 20\% = "<<ntugas $<<"$ "<<uts $<<" \quad$ x $30 \%=$ "<<nuts $<<$ " "<<uas $<<" \quad$ x $50 \%=$ "<<nuas $<<$ " "<<endl;

cout $<<$ endl;

cout $<<$ endl;

----------------" "<<endl;

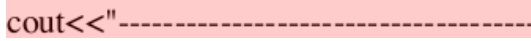

MAHASISWA"<<endl; 
cout $<<$ "Total Nilai yang di dapatkan = $"<<$ total $<<$ endl;

cout $<<"$

-----------------" $<<$ endl;

$\operatorname{getch}()$;

\}

c. Visual Basic

Awalnya berasal dari bahasa pemrograman BASIC dimana sangat dikenal pada saat komputer pertama kali diperkenalkan. Bahasa pemrograman ini memungkinkan suatu aplikasi dapat dibuat dengan cepat dan mudah.

Contoh:

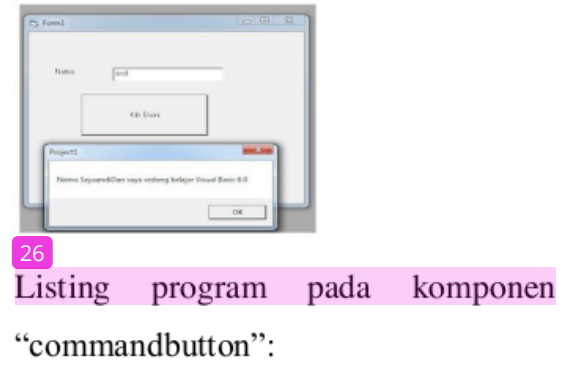

If Text1.Text $=$ " " Then

MsgBox ("Isi dulu Nama anda")

Else
26

MsgBox ("Nama Saya" + Text1.Text + "Dan saya sedang belajar Visual Basic 6.0")

End If

3. Perangkat Lunak Aplikasi

Program pemrograman disiapkan untuk menggunakan program yang nantinya akan digunakan untuk membantu menyampaikan perjalanan pekerjaan. Contoh dari programaplikasi adalah sebagai berikut:

1. Word Handling adalah program yang dapat digunakan untuk mengubah salinan asli. Model: Microsoft Word

2.Program halaman akuntansi adalah untuk menangani informasi pada bagian-bagian. Model: Microsoft Dominate, Lotus Comedy.

\section{Program Unility}

Program unitily atau sebaliknya Program Administrasi adalah program PC yang secara khusus dimaksudkan untuk membantu mengawasi dan mengubah perangkat, kerangka kerja, atau program aplikasi dengan memainkan perangkat apa pun atau 


$$
\begin{aligned}
& \text { sedikit usaha. Ilustrasi program } \\
& \text { Solidaritas adalah sebagai berikut: } \\
& \text { 1. Disk Defragmenter adalah salah } \\
& \text { satu tool yang disediakan oleh } \\
& \text { Windows yang digunakan untuk } \\
& \text { menganalisa volume Drive, dan } \\
& \text { untuk mengalokasikan dan } \\
& \text { mengkonsolidasikan ulang file- } \\
& \text { file ataupun folder-folder yang } \\
& \text { terpisah. } \\
& \text { 2.Driver merupakan suatu aplikasi } \\
& \text { untuk menghubungkan beragam } \\
& \text { perangkat keras, ke komputer } \\
& \text { dna terhubung melalui } \\
& \text { perangkat lunak }
\end{aligned}
$$

3. diskatau file yang dipilih.

\subsection{Sistem}

\section{Informasi}

\section{Manajemen}

Sistem Informasi Manajemen adalah kerja data yang selain melakukan semua penanganan pertukaran yang dibutuhkan oleh asosiasi, juga menjunjung tinggi data dan penanganan untuk melakukan aktivitas eksekutif dan kapasitas dinamis. Banyaknya kemajuan ini harus dimanfaatkan jika didukung oleh SDM yang mumpuni. Karena penggunaan PC dan inovasi data dalam kehidupan kita sangat tak terhindarkan dan terkenal, penggunaan kerangka kerja data administrasi berbasis PC adalah kebutuhan yang mutlak, dan dapat memberikan keunggulan.

Dapat disimpulkan bahwa sistem informasi manajemen dapat diibaratkan sebagai darah yang mengalir dalam tubuh manusia, dimana informasi menjadi hal yang sangat penting bagi perusahaan untuk mendukung kelangsungan perkembangannya, sehingga menjadi alasan mengapa informasi tersebut dibutuhkan untuk sebuah perusahaan. Akibatnya jika tidak memperoleh informasi dalam kurun waktu tertentu maka perusahaan tidak akan dapat mengontrol sumber dayanya, sehingga akan sangat terganggu ketika mengambil keputusan strategis dan pada akhirnya akan dikalahkan oleh pesaing.

Sistem Informasi 29 Manajemen merupakan sebuah sistem yang terdiri dari beberapa komponen yang saling berkesinambungan dengan baik sehingga mencapai tujuan yang ingin dicapai. Secara umum terdapat 3 kegiatan utama SIM yaitu: menginput data (input), memproses data, dan menghasilkan informasi (output).Setiap kegiatan didalam dunia pendidikan sangat memerlukan informasi yang 
baik, seperti dalam perencanaan, pengorganisasian, pelaksanaan dan pengawasan. Setiap kegiatan tersebut sangat memerlukan sebuah informasi, karena sebuah informasi merupakan landasan dan pedoman dalam melakukan tindakan dan kegiatan. Serta dalam pengambilan keputusan sebuah informasi sangat diperlukan juga, dengan sistem informasi manajemen ini, kita dapat mengakses sebuah informasi dengan cepat dan informasi yang dihasilkan tersebut akurat dan dapat dipercaya, sehingga memudahkan kita dalam melakukan pengambilan keputusan (Novad, 2019).

\subsection{Fungsi Sistem Informasi Manajemen}

1. Memudahkan bagian manajemen melakukan perencanaan, pengawasan, serta pengarahan kerja bagi semua departemen yang dikoordinirnya.

2.Meningkatkan efektivitas dan efesiensi pengolahan data,karena data yang ada sistem informasi suatu manajeen merupakan data telah tersaji secara akurat dan real time (tepat waktu).
3. Meminimalisir biaya dan suatu perusahaan atau organisasi.

4.Sarana peningkataan SDM, karena dalam pelaksanaannya diperlukan unit kerja yang sistematis serta terkoordinir berbasis teknologi.

(idCloudHost, 2019).

\subsection{Tujuan Sistem Informasi Manajemen \\ Tujuan sistem informasi suatu} manajemen diantaranya adalah sebagai berikut:

1. Menyediakan produk berupa barang ataupun jasa yang merupakan target utama SIM

2. Menyediakan layanan yang dapat dipergunakan menjadi media pengendali, perencana, evaluasi serta sebagai sarana perbaikan berkelanjutan.

3. Menyediakan informasi pendukung yang dapat dipergunakan untuk analisi dan pengambilan keputusan dan suatu perusahaan.

4. Secara garis besar sistem informasi suatu manajemen bertujuan untuk memudahkan pekerjaan dan pengelolaan manajemen dalam suatu 
perusahaan (idCloudHost, 2019).

\subsection{Manfaat}

\section{Informasi Manajemen}

1. Dapat mengharapkan dan memahami peluang finansial kerangka data yang menerapkan inovasi data baru.

2. Dapat membantu menjamin kualitas dan kemampuan SDM dalam menggunakan kerangka data administrasi.

3. Dapat bekerja dengan penerimaan informasi yang telah diberikan secara tepat dan progresif (sesuai jadwal) untuk klien tanpa perlu melalui pendelegasian kerangka data secara langsung.

4. Dapat menumbuhkan persiapan yang lebih ideal dan bertenaga.

5. dapat membantu melakukan pendekatan pemrograman dan ID dukungan kerangka kerja data.

6. Dapat lebih mengembangkan kegunaan dan kemajuan dalam kerangka administrasi, seperti penanganan pertukaran untuk membatasi biaya dan meningkatkan pendapatan

(idCloudHost, 2019).

1.6 Karakteristik Sistem Informasi

1.SIM membantu manajer secara terstruktur.

2.SIM dirancang untuk memberikan laporan operasional sehari-hari.

3.SIM sangat bergantung pada keberadaan data organisasi secara keseluruhan.

4.SIM membutuhkan perencanaan yang matang.

\subsection{Konsep-konsep Pokok} dalam SIM

1.Penyajian informasi dengan waktu dan mutu menambah nilai tersendiri pada Informasi.

2. Gagasan tentang manusia sebagai pemroses data kemampuan manusia seorang sebagai pemroses data membatasi kerangka kerja data dan membuat tujuan penting.

3. Ide Kerangka Mengingat fakta bahwa kerangka kerja administrasi data adalah kerangka kerja, pendapat sebuah kerangka kerja sangat penting untuk 
dipahami dan rencana konfigurasi untuk peningkatan kerangka kerja data.

4. Asosiasi dan Kerangka kerja Ide eksekutif Data berada di dalam asosiasi dan dimaksudkan untuk membantu kapasitas dewan. Data adalah penentu signifikan dari struktur otoritatif.

5.Konsep Pengambilan Keputusan

Rancangan SIM bukan hanya harus mencerminkan ancangan rasional terhadap optimasi, tetapi juga teori keprilakuan pengambilan keputusan dalam organisasi.

\section{Konsep Nilai Informasi}

Informasi mrngubah keputusan, perubahan dalam nilai hasil akan menentukan nilai informasi. Di dalam sebuah organisasi atau perusahaan sistem informasi bersifat terbuka, dimana sistem informasi saluang terhubung dengan sistem lain .(Setiorinishinta, 2016).

35

\subsection{Peran Strategi Sistem}

Informasi Manajemen
Sistem Informasi managemen merupakan Kumpulan dari Sistem Informasi

1.Kerangka data pembukuan memberikan data moneter dan pertukaran.

2.Menampilkan kerangka kerja data memberikan data untuk penawaran, kemajuan penawaran, latihan survei statistik, dll yang terkait dengan periklanan.

3. Kerangka data administrasistok.

4. Kerangka data individu.

5.Kerangka data dispersi.

6. Beli kerangka data.

7. bingkai data kelimpahan.

8. kerangka data investigasi kredit.

9.Kerangka kerja data kerja yang inovatif.

10. Pemrograman investigasi kerangka data.

11. Kerangka data khusus.

1.9 Integrasi Sistem Informasi

Pengintegrasian sistem informasi merupakan salah satu konsep kunci dari sistem informasi manajemen. Berbagi sistem dapat saling berhubungan satu dengan yang lain dengan berbagai cara vang sesuai dengan keperluannya. Keuntungan utama dari integrasi sistem 
informasi adalah membaiknya arus

informasi dalam sebuah informasi. Keuntungan ini merupakan alasan yang kuat untuk mengutamakan sistem informasi terintegrasi karena tujuan utama dari sistem informasi adalah memberikan informasi yang benar pada saat yang tepat.

Keuntungan lain dari prngintegrasian sistem adalah sifatnya yang mendorong manajer untuk membagikan (mengkomunikasikan) informasi yang dihasilkan oleh departemen (bagian) nya agar secara rutin mengalir ke sistem lain yang memerlukannya. Informasi ini kemudian digunakan lebih luas untuk membantu organisasi (Jenni Veronika Br. Ginting, 2015)

\section{KESIMPULAN}

Perangkat lunak adalah suatu istilah generik yang merujuk pada jenis perangkat lunak komputer yang mengatur dan mengontrol perangkat keras sehingga pemrograman aplikasi dapat melakukan pengujian. Windows merupakan framework kerja yang dibuat oleh Microsoft, dimana framework kerja ini memberikan titik interaksi grafis (GUI/Graphical UI) agar lebih mudah untuk bekerja. UNIX adalah kerangka kerja yang mengejutkan yang bentuknya dapat berjalan di PC server mini dan terpusat. UNIX adalah perangkat lunak gratis, setiap orang dapat tanpa hambatan menguranginya dan menyesuaikannya agar sesuai dengan kebutuhan mereka sendiri. UNIX juga memiliki varian eksklusif (atau pedagang akan membebankan biaya untuk menggunakan atau membeli sistem kerja). Pedagang membuat adaptasi UNIX mereka menjadi terbatas dengan menambahkan elemen ke kerangka kerja yang memperluas elemen standar varian UNIX gratis. Pedagang ini benar-benar menawarkan bentuk UNIX gratis (yang kadang-kadang disebut bentuk "terbuka" tetapi mereka juga sangat bergantung pada varian yang mereka miliki yang dapat mereka tawarkan kepada pelanggan. Linux adalah sistem kerja yang menggunakan bagian linux. Bagian yang sebenarnya sangat penting untuk kerangka kerja yang dapat digunakan untuk mengawasi prosesor komputer, memori dan berbagai upgrade Linux adalah sistem operasi open source, yang berarti kode sumber linux, apa yang lebih diambil tanpa syarat oleh siapa pun. Lisensi Linux di bawah dukungan GNU juga 
gratis, kita tidak perlu membayar apa pun untuk menggunakannya. DOS atau

Plate Working Framework adalah bagian dari pemrograman yang memiliki tempat dengan kumpulan kerangka kerja yang penting. Intinya, kita bisa mengamati DOS di Windows saat kita membuka program CMD. Kerangka Data Eksekutif adalah kerangka kerja data yang selain menyelesaikan semua penanganan pertukaran yang dibutuhkan oleh asosiasi, juga menjunjung tinggi data dan penanganan untuk melakukan tugas-tugas dewan dan kapasitas dinamis..

\section{DAFTAR PUSTAKA}

https://kamus.tokopedia.com/p/perangk $\underline{\text { at-lunak }}$

(https://sg.docworkspace.com/d/sIHekg Nhjua2xjgY)

https://tirto.id/definisi-komputermenurut-para-ahli-sanders-hinggablissmer-gc 94

(https://id.m.wikipedia.org/wiki/Sistem _informasi_manajemen)

(https://scholar.google.co.id/scholar?cl $\underline{\text { uster }=15852987918228933286 \& \mathrm{hl}=\mathrm{id}}$ \&as $\mathrm{sdt}=0,5 \# \mathrm{~d}=\mathrm{gs}$ qabs\& $\mathrm{u}=\% 23 \mathrm{p} \% 3$

DLUz8SSVRicll)

(https://kamus.tokopedia.com/p/perang

kat-lunak)

(https://www.nesabamedia.com/penger $\underline{\text { tian-windows-dan-sejarah-windows/) }}$

(https://id.m.wikipedia.org/wiki/Unix)

(https://www.nesabamedia.com/penger tian-unix/)

(https://brainly.co.id/tugas/1788519)

(https://scholar.google.co.id/scholar?hl $=\mathrm{id} \&$ as sdt $=0 \% 2 \mathrm{C} 5 \& \mathrm{q}=$ analisa + peran gkat+lunak+mengenai+LINUX\&btnG $=\# \mathrm{~d}=\mathrm{gs}$ qabs $\& \mathrm{u}=\% 23 \mathrm{p} \% 3 \mathrm{DozHwOV}$ 3g9mgJ)

(https://www.dosenpendidikan.co.id/do s-adalah/)

(https://id.m.wikipedia.org/wiki/DOS)

(https://p2k.unkris.ac.id/id1/1-30652962/Ms-Dos_24651_p2k-unkris.html) (https://id.m.wikipedia.org/wiki/PHP) 
(https://qwords.com/blog/contoh-

program-c/)

(http://blog.ub.ac.id/danarjoeditja/2013

$\underline{\text { /03/17/48/) }}$

Samsudin, (2019) "Pengenalan

Komputer Dan Teknologi Informasi"

Seprida Hanum Harahap (2017)

"Sistem Informasi Akuntansi"

Sutabri Tata, (2016) "Sistem Informasi

Manajemen"

Abdul Karim, (2020) "Teknologi

Informasi dan Sistem Informasi

Manajemen" 


\section{ANNISA_0702212233_PIK_jurnal.docx}

ORIGINALITY REPORT

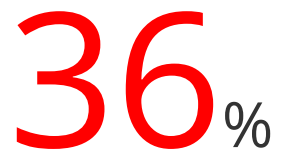

SIMILARITY INDEX

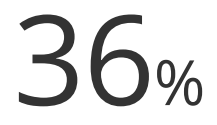

INTERNET SOURCES
$3 \%$

PUBLICATIONS
$9 \%$

STUDENT PAPERS

PRIMARY SOURCES

1 wWw.coursehero.com

Internet Source

2 anniishavreimentverdorben.blogspot.com Internet Source

3 repository.uinsu.ac.id Internet Source

4 www.nesabamedia.com

Internet Source

5 nonosun.staf.upi.edu

Internet Source

6 jurnalitas.blogspot.com

Internet Source

7 tirtalsmn.blogspot.com 
10 nanopdf.com

11 hmsistmiknh.blogspot.com

kamus.tokopedia.com

Internet Source

13 ruangguru.co

Internet Source

14 pt.scribd.com

Internet Source

15 www.administrasipublik.com

Internet Source

16 rezaamazing.blogspot.com

Internet Source

17 id.wikipedia.org

Internet Source

tl301.ilearning.me

Internet Source

19 WWW.artikelkomputerku.com

Internet Source

www.dosenpendidikan.co.id

Internet Source 


\section{Submitted to Sriwijaya University}

25 amp.tirto.id

26 dosenit.com

Internet Source

27 kevinbakkara.wordpress.com

28 www.hostinger.co.id

29 repository.unpas.ac.id

30 123dok.com

31 fungsi.co.id 
34 jasa-web-murah.blogspot.com

35 setiorinishinta.wordpress.com

36 hanifa5235122734.wordpress.com

37 marianiakuntan.blogspot.com

Internet Source

Muhammad Afif Zamroni. "Penerapan Sistem

Informasi Manajemen Pendidikan dalam

Proses Pembelajaran di SMP Negeri 1

Dlanggu", Munaddhomah: Jurnal Manajemen

Pendidikan Islam, 2020

Publication

39

arsitekkomputer.blogspot.com

Internet Source

40 defibungsyu.blogspot.com

41 hanifsaeful.wordpress.com

Internet Source

42 arissupri.blogspot.com

Internet Source 
